\title{
An Integrated Human Reliability Based Decision Pool Generating and Decision Making Method for Power Supply System in LNG Terminal
}

\author{
Renyou Zhang, Henry Tan \\ Lloyd's Register Foundation (LRF) Centre for Safety and Reliability Engineering, School of \\ Engineering, University of Aberdeen, Aberdeen AB24 3UE, UK
}

\begin{abstract}
In this paper, an integrated model is presented to support human reliability based decision producing and making process by evaluating safety promotion plan for power supply system in LNG (Liquid Natural Gas) terminal. This model is mainly mathematically treated through fuzzy Cognitive Reliability and Error Analysis Method (CREAM) in combination with Genetic Algorithms (GA) and Adaptive Neuro-Fuzzy Inference System (ANFIS). The fuzzy CREAM accounts the operators' individual factors, organization factors, environmental factors and technique factors together to identify the fuzzy membership degree of each control mode and to calculate Human Error Probability (HEP). However, when the calculated HEP fails to meet the requirement, the GA will identify the target membership degree of each CREAM control mode, and adopting such target membership degree and fuzzy logic rule to generate a decision pool for safety promotion. Finally, an experts' evaluation result based ANFIS provides a standard evaluating system for plan choice and update. The proposed model has been tested on a power supply system for an LNG terminal in Beihai China.
\end{abstract}

Keywords: Human reliability based; Fuzzy CREAM; Decision producing and making; Genetic algorithms; ANFIS

\section{Introduction}

According to the statistical data from 1964 to 2005, the frequency of accidents during LNG offloading is one of the highest among all (Vanem et al., 2008), and during the shipping LNG offloading activity in LNG terminal, the power supply system is a key factor to guarantee the operation running normally. So ensuring and improving the safety performance of power supply system is crucial to avoid the consequence. Maintaining the power supply system is mainly human related work, and according to many accidents' reports, human factors are important reasons that trigger the over $60 \%$ of catastrophic accidents in the commercial shipping and process industry (Wiegmann and Shappell, 2001; Dhillon, 2007; Casal and Olsen, 2016). Therefore, a human reliability based plan for safety promotion in power supply system is necessary. However, under many situations, the HEP data calculated by Human Reliability Analysis (HRA) methods are mostly viewed as simply values with limited applications and even fail to reach the requirements, and unfortunately, there is inadequate research to tackle such situation. Therefore, this study is aiming to extend HRA application and to find the valuable information behind the HEP data to provide a safety promotion plan evaluating model for power supply system in an LNG terminal.

Human reliability has received systematic research since the Second World War, due to remarkable acceleration in military technology (Swain, 1990). Two generations of Human Reliability Analysis (HRA) methods have been developed. The source idea of the first generation methods mainly results from the inherent deficiencies of human (Marseguerra et al., 2006). The widely used first generation methods include Task-based Technique for Human Error Rate Prediction, Human Error Assessment and Reduction Technique, Success Likelihood Index Methodology, etc. (Kim and Bishu, 2006). 
However, as extensive studies of human performance have illustrated that the importance of the outside environmental conditions in which the task is performed is greater than the natures of the task itself, the first generation HRA method has been doubted for over 20 years (Yang et al., 2013).

For the sake of addressing the shortcoming of first generation methodology, the second generation method has been developed which includes Cognitive Event Tree System, Human Interaction Time Line, Connection Assessment of Human Reliability, and CREAM. Among them, CREAM is the most well-known method. The CREAM method integrates the operators' individual factors, organization factors, environmental factors, and technique factors together. Nine Common Preference Conditions (CPCs) are introduced to evaluate and decide the Contextual Control Model (COCOM). As listed in Table 1, nine CPCs are adequacy of organisation, working condition, adequacy of man-machine interface and operational support, availability of procedures and plans, number of simultaneous goals, available time, time of day, adequacy of training and experience, and crew collaboration quality. The COCOM contains four kinds of control modes: strategic, tactical, opportunistic, and scrambled (Hollnagel, 1998). Each COCOM has its corresponding HEP interval. CREAM has been used in many industrial practices including the offshore oil platform operation (Turan and El-laden, 2012), LPG terminal operation (Akyuz and Celik, 2015), nuclear power plant operation (He et al., 2008; Ribeiro et al., 2016), and maritime industry operation such as oil tanker ship operation (Akyuz, 2015; Ung, 2015; Zhou et al., 2017). Additionally, many improvements have been applied on CREAM, sensitivity and uncertainty of CREAM have been analysed with the consideration of different cognitive failure modes to improve the CREAM (Bedford et al., 2013), and the revised CPCs are provided for tanker shipping activity (Zhou et al., 2017); moreover, for the sake of dealing with the uncertainty and imprecision during CREAM process, fuzzy logic and Fuzzy Analytic Hierarchy Process (FAHP) are introduced to increase the accuracy of CREAM (Konstandinidou et al., 2006; Ung, 2015; Zhou et al., 2017).

This research adopts fuzzy CREAM for HRA, and the defuzzification process on CREAM to give the calculated HEP, but under the situation that such calculated HEP fails to meet the requirement of HEP, some methods should be provided. Facing this situation, implementing GA on defuzzification process, and viewing the required HEP and defuzzification function as the target and the objective function respectively, then the target membership of each COCOM in fuzzy CREAM can be identified. According to the theory of fuzzy CREAM, through changing the performance data of one/some CPCs, the target membership degrees of COCOM will be achieved, and the corresponding calculated HEP will be accepted. Besides, there are 9 CPCs in CREAM form, and each CPC contains several subinfluence factors which are shown in Appendix A. Therefore, there are many potential passages to reach the target membership degrees to fulfil the HEP requirement. In other words, the CREAM can be extended as a tool to construct a plan pool for promoting human reliability and system safety. After that, facing those defined choices, a decision making process is needed. Obviously, this is a multicriteria decision making (MCDM) problem, and the experienced experts evaluate each defined plan, then an Adaptive Neural Fuzzy Inference System (ANFIS) is constructed based on experts' evaluation results to simulate the experts' decision process for future plan evaluating and updating. (Golmohammadi, 2011; Özkan and İnal, 2014; Azadeh et al., 2016). In summary, the description above forms the major contribution of this paper.

In this paper, the work extending the fuzzy CREAM from a simply HRA method to a method that can generate a pool of safety promotion plans will be presented and based on a power supply system in LNG terminal. Then based on the experts' evaluation results, ANFIS is used to provide a standard system for plan updating and evaluating. The structure of this paper is as following. In section 2, the 
framework of this method is explained; in section 3, the description of chosen methods are presented; in section 4, a real example is illustrated to approve the method; in section 5, the conclusion is given, and the future work is discussed.

\section{The framework of the proposed approach}

A flow diagram of method process is shown in Fig.1, and the main steps are briefly explained as follows.

Step 1-Fuzzification: The aim of this stage is to determine the fuzzy membership degrees for nine CPCs.

Step 2-Fuzzy CREAM calculation: After defining and inputting the fuzzy membership degree data, through fuzzy logical rules and based on CREAM, the membership of the control mode can be identified.

Step 3-Defuzzification: In this part, with the membership degree of each control mode, the HEP can be calculated by taking membership degree data of COCOM into defuzzification method "Centre of Area (COA)" (Ung, 2015; Ung and Shen, 2011).

Step 4-Finding the target fuzzy membership degrees: If the calculated HEP fails to achieve the requirement, the required HEP value will be set as an objective, and GA will be applied on the defuzzification process (COA equation) to find target membership degree of each COCOM within the objective and each constraint.

Step 5-Potential plans identification: Once the target membership degree of each COCOM is identified, using such membership degree as target, and then through improving the performance of one/some CPCs, a plenty of potential safety promotion plans will be produced. Namely, through different ways to change the performance data of some CPCs to reach the target membership degrees, so to ensure the calculated HEP is acceptable.

Step 6-Construction of decision making model: In this step, all potential plans are evaluated by experienced experts, and the experts' evaluation results based ANFIS is adopted to simulate the human decision making process and to build a standard and robust decision making system for future plan evaluating and updating for this system. 


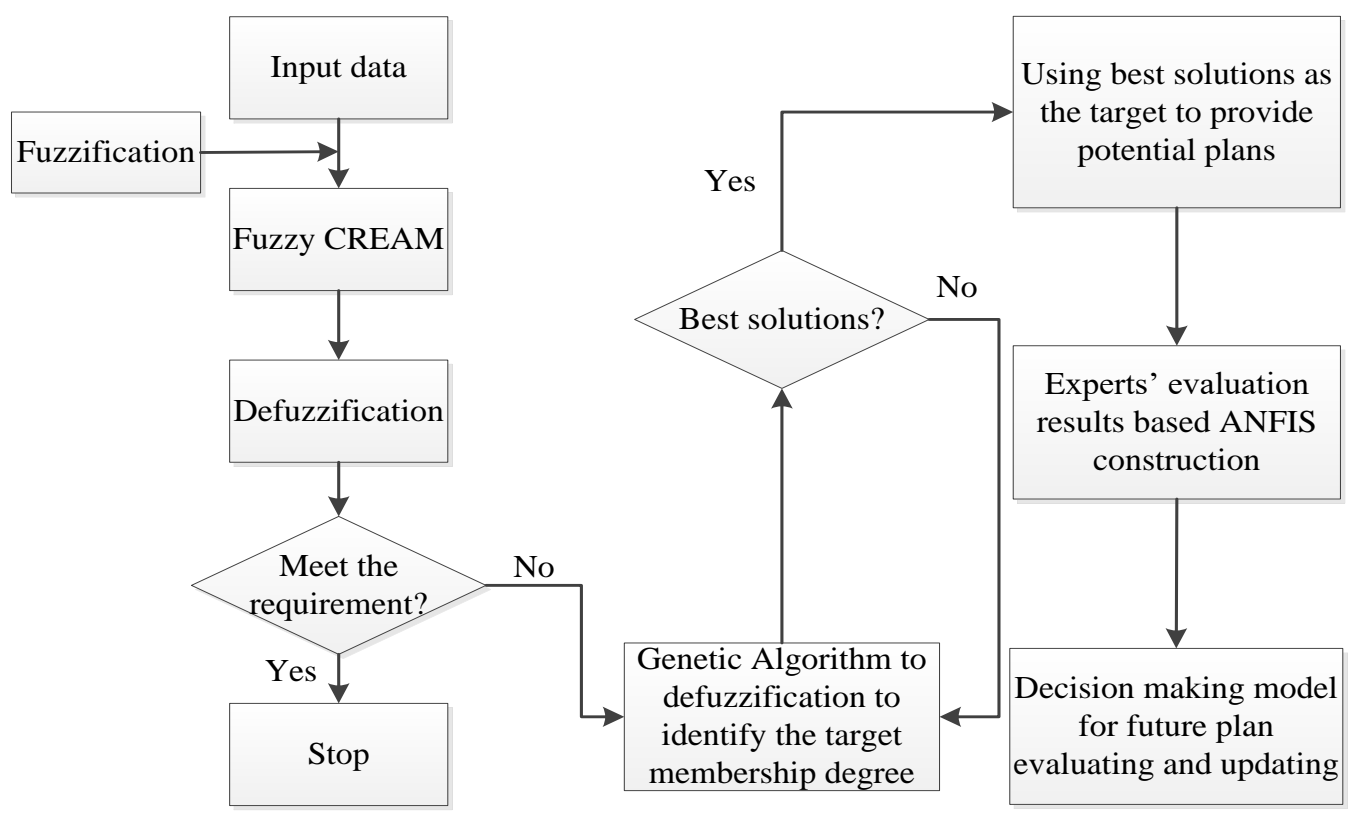

Fig.1. The flow diagram of the methodology

\section{Research methodologies}

This paper introduces a modified version of CREAM so that it not only can be used for HRA, but also can be extended as a medium for safety promotion plan generating and deciding.

\subsection{Fuzzy CREAM}

Because the subjective opinion becomes a crucial shortcoming to HRA and there is a lack of human error database, if-then rule based fuzzy logic, which is useful in dealing with uncertainty data, has been incorporated in CREAM (Konstandinidou et al., 2006). The evaluation form of CREAM is displayed as Table 1. In this form, each CPC has several levels, and different levels have different effects on reliability. As shown in Table 1, "+1", "0", and "-1" are introduced to represent the positive effect, no effect, and negative effect on human reliability performance respectively. Additionally, in this paper, for simplification, the weights of each CPC for human reliability calculating are assumed to be equally distributed.

Table 1. The CREAM evaluation form

\begin{tabular}{lcc}
\hline CPC name & Level & Effect on reliability \\
\hline & Very efficient & Improved (+1) \\
1.Adequacy of organization & Efficient & Not significant $(0)$ \\
& Inefficient & Reduced (-1) \\
& Deficient & Reduced (-1) \\
& Advantageous & Improved (+1) \\
& Compatible & Not significant $(0)$ \\
2.Working condition & Incompatible & Reduced $(-1)$ \\
& & \\
& Supportive & Improved $(+1)$ \\
3.Adequacy of Man & Adequate & Not significant $(0)$ \\
Machine Interface (MMI) & Tolerable & Not significant $(0)$ \\
and operational support & Inappropriate & Reduced $(-1)$ \\
& &
\end{tabular}




\begin{tabular}{|c|c|c|}
\hline $\begin{array}{l}\text { 4.Availability of procedures/ } \\
\text { plans }\end{array}$ & $\begin{array}{l}\text { Appropriate } \\
\text { Acceptable } \\
\text { Inappropriate }\end{array}$ & $\begin{array}{c}\text { Improved }(+1) \\
\text { Not significant }(0) \\
\text { Reduced }(-1)\end{array}$ \\
\hline $\begin{array}{l}\text { 5.Number of simultaneous } \\
\text { goals }\end{array}$ & $\begin{array}{l}\text { Fewer than capacity } \\
\text { Matching current capacity } \\
\text { More than capacity }\end{array}$ & $\begin{array}{l}\text { Not significant }(0) \\
\text { Not significant }(0) \\
\text { Reduced (-1) }\end{array}$ \\
\hline 6.Available time & $\begin{array}{c}\text { Adequate } \\
\text { Temporarily inadequate } \\
\text { Continuously inadequate }\end{array}$ & $\begin{array}{l}\text { Improved }(+1) \\
\text { Not significant }(0) \\
\text { Reduced }(-1)\end{array}$ \\
\hline 7.Time of day & $\begin{array}{l}\text { Day } \\
\text { Evening } \\
\text { Night }\end{array}$ & $\begin{array}{l}\text { Not significant (0) } \\
\text { Reduced (-1) } \\
\text { Reduced (-1) }\end{array}$ \\
\hline $\begin{array}{l}\text { 8.Adequacy of training and } \\
\text { expertise }\end{array}$ & $\begin{array}{c}\text { Adequate high experience } \\
\text { Adequate, limited } \\
\text { experience } \\
\text { Inadequate }\end{array}$ & $\begin{array}{c}\text { Improved (+1) } \\
\text { Not significant (0) } \\
\text { Reduced (-1) }\end{array}$ \\
\hline 9. Crew collaboration quality & $\begin{array}{l}\text { Very efficient } \\
\text { Efficient } \\
\text { Inefficient } \\
\text { Deficient }\end{array}$ & $\begin{array}{c}\text { Improved }(+1) \\
\text { Not significant }(0) \\
\text { Not significant }(0) \\
\text { Reduced }(-1)\end{array}$ \\
\hline
\end{tabular}

During the CREAM application, Fig.2 and Context Influence Index (CII) are introduced to decide the COCOM. The CII value is determined by Eq. (1).

$$
\text { CII }=\sum \mid \text { Reduced }\left|-\sum\right| \text { Improved } \mid
$$

where $\sum \mid$ Reduced $\mid$ and $\sum \mid$ Improved $\mid$ are the total number of CPCs with reduced reliability effect (-1) and improved reliability effect $(+1)$ as described in Table 1 , respectively.

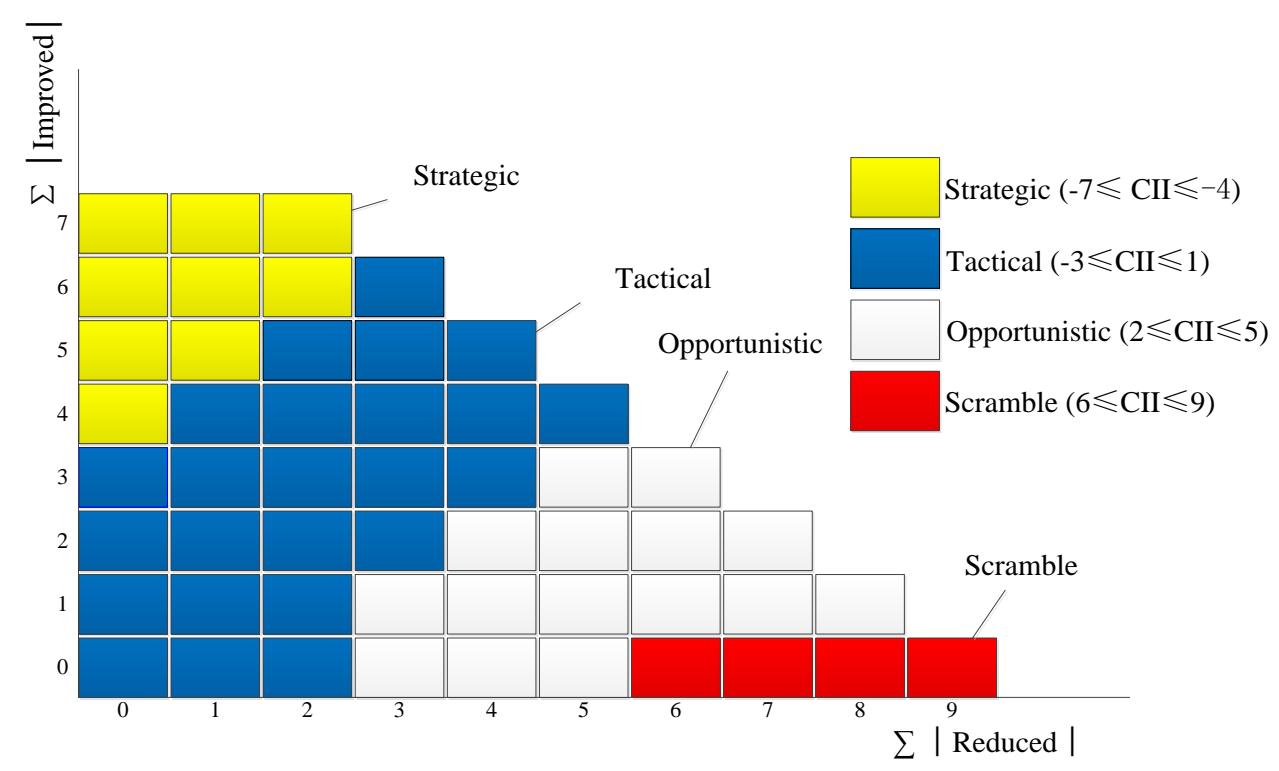

Fig.2. The relationship of each CPC and COCOM.

The HEP interval, the logarithm interval of each COCOM, and the CII value as defined by Table 2 .

Table 2. HEP and $\log _{10}$ HEP interval of each COCOM (Sun et al., 2012) 


\begin{tabular}{cccc}
\hline COCOMs & HEP interval & $\log _{H E P}$ interval & CII values \\
\hline Strategic & $0.00005<\mathrm{HEP}<0.01$ & $-5.3<\log _{H E P}<-2$ & $-7 \leq \mathrm{CII} \leq-3$ \\
Tactical & $0.001<\mathrm{HEP}<0.1$ & $-3<\log _{H E P}<-1$ & $-3 \leq \mathrm{CII} \leq 1$ \\
Opportunistic & $0.01<\mathrm{HEP}<0.5$ & $-2<\log _{H E P}<-0.3$ & $2 \leq \mathrm{CII} \leq 5$ \\
Scrambled & $0.1<\mathrm{HEP}<1.0$ & $-1<\log _{H E P}<0$ & $6 \leq \mathrm{CII} \leq 9$ \\
\hline
\end{tabular}

However, under most situations, the boundaries of different levels in CPCs and COCOMs are unclear, fuzzy logic is therefore utilised in CREAM to evaluate each CPC and to determine the membership level of COCOMs. The if-then rule based fuzzy logic operations are shown as Eq. (2).

$$
\left\{\begin{array}{c}
\mu_{\min }^{m}=\mu_{m}^{1} \wedge \mu_{m}^{2} \wedge \cdots \mu_{m}^{i}(m=1,2,3 \cdots M, i=1.2 \cdots 9) \\
\mu_{\max }=\mu_{\min }^{1} \vee \mu_{\min }^{2} \vee \cdots \mu_{\min }^{M^{\prime}}
\end{array}\right.
$$

where, $\mu_{m}^{i}$ is the fuzzy membership degree of $i$ th CPC in $m$ th if-then rule, $M$ is the total number of ifthen rules, $\mu_{m i n}^{m}(m=1,2, \cdots M)$ is the minimum fuzzy degree data among all $\mu_{m}^{i}$ in $m$ th if-then rule, $\mu_{\max }$ is the maximum fuzzy degree among all fuzzy degrees under a certain COCOM, $M^{\prime}$ is the number of if-then rules under such COCOM. Then the trapezoid fuzzy membership function is chosen to express the fuzzy data and to avoid too many fuzzy data. In this paper, the trapezoid membership function, denoted as $\mu_{[a, b, c, d]}(x)$, is adopted which takes the form as Eq. (3).

$$
\mu_{[a, b, c, d]}(x)=\left\{\begin{array}{cc}
0 & (x \leq a) \\
\frac{x-a}{b-a} & (a \leq x \leq b) \\
1 & (b \leq x \leq c) \\
\frac{d-x}{d-c} & (c \leq x \leq d) \\
0 & (x \geq d)
\end{array}\right.
$$

where $x$ can be the mark in range from 0 to 100, or the logarithm of HEP data.

With the fuzzy membership data of each CPC, the membership degree of each control mode can be determined. Then the Centre of Area (COA) (defuzzification method) shown in Eq. (4) is adopted for calculating the HEP result.

$$
\log _{10} H E P=\frac{\sum_{i=1}^{n}\left[\int_{x_{L}^{i^{\prime}}}^{x_{U}^{i^{\prime}}} \mu_{i^{\prime}}(x) x d x\right]}{\sum_{i=1}^{n}\left[\int_{x_{L}^{i^{\prime}}}^{x_{i^{\prime}}^{i^{\prime}}} \mu_{i^{\prime}}(x) d x\right]}
$$

where, $x$ is the logarithm of HEP data, $\mu_{i^{\prime}}(x)$ is the $i^{\prime}$ th expression of the corresponding fuzzy membership function, and the corresponding upper and lower limits of the integration for $i^{\prime}$ th membership function are expressed by $x_{U}^{i^{\prime}}$ and $x_{L}^{i^{\prime}}$.

\subsection{GA optimization}

GA technique, developed at the University of Michigan by John Holland in the late 1960s (Konak et al., 2006), and is inspired by the observation of the biological phenomenon. GA is considered as a smart searching tool which focuses on the objective function with one or more variables, and possibly subject to some linear and/or nonlinear constraints (Innal et al., 2015; Torres-Echeverria et al., 2009). As both linear problems and nonlinear problems can be friendly operated by GA optimization, GA is stronger than linear programming; in addition, compared with other optimization methods such as Particle Swarm Optimization and Ant Colony Algorithm, GA is good in finding the global solutions with less iteration, so GA is adopted for this study. Fig. 3 shows the flow chart of GA optimization. 


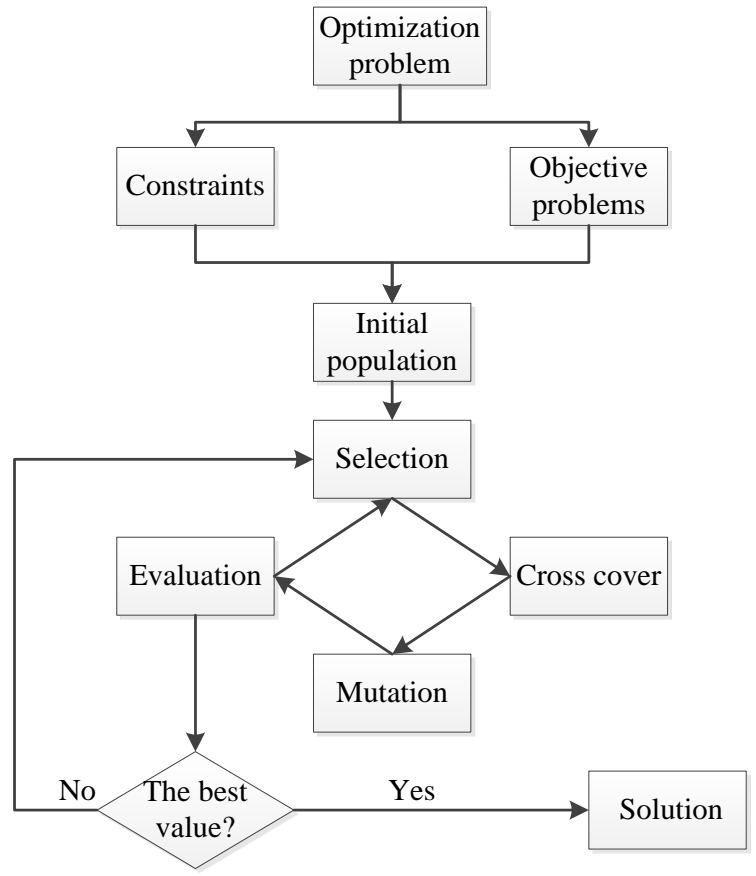

Fig.3. The flow chart of GA optimization

The GA starts with the objective identification, and then the objective function and the constraints should be determined. The objective function is normally determined by the requirements of the study, so the objective functions and corresponding constraints for this research will be explained in the section "Case study". After that, GA process can be carried out to find the global solution which can meet the objective within the constraints. In summary, the main advantages of GA optimization are 1) the method is friendly to use (MATLAB, 2009); 2) it will not take long time to finish the optimization (this project takes 10 minutes); 3) GA optimization can find the global solution in relatively high efficiency.

\subsection{ANFIS}

ANFIS is a kind of artificial intelligence method and has been used for clustering, pattern recognition regression, and decision making (Abbasi and Mahlooji, 2012). This method is a feed-forward neural network which integrates fuzzy logic and neural network together (Özkan and İnal, 2014). The fuzzy rules are used to treat the input data, and the neural network is worked as a way to finish the training process. During the ANFIS process, the gradient descent method and the least square methods are used to train the fuzzy inputs (Özkan and İnal, 2014). A two-input ANFIS model is shown in Fig.4 as an example, and five layers are included in ANFIS structure to process the data. 


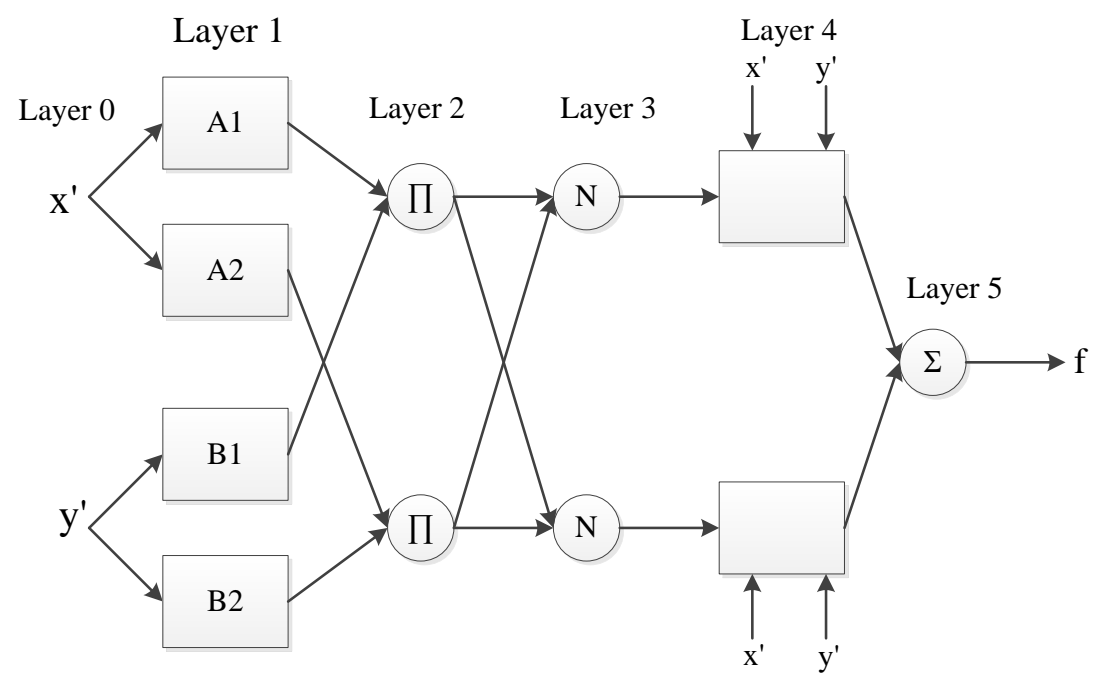

Fig.4. The basic architecture of ANFIS (Sarkheyli et al., 2015).

Layer 1: This layer is the input layer, the fuzzy membership function is utilised to express the raw data from layer 0 , and the output of layer $1, O_{1, k}$ is

$$
O_{1, k}=\left\{\begin{array}{l}
\mu_{A_{k}}\left(x^{\prime}\right)(k=1,2) \\
\mu_{B_{k}}\left(y^{\prime}\right)(k=1,2)
\end{array}\right.
$$

where $\mu_{A_{k}}\left(x^{\prime}\right)$ and $\mu_{B_{k}}\left(y^{\prime}\right)$ are fuzzy membership function for input $x^{\prime}$ and $y^{\prime}$.

Layer 2: This layer represents the if-then rules in fuzzy logic to model the training data set (Wei, 2016). Every incoming signal multiplication based on Eq. (6) displayed below:

$$
O_{2, k}=w_{k}=\mu_{A_{k}}\left(x^{\prime}\right) \times \mu_{B_{k}}\left(y^{\prime}\right)(k=1,2)
$$

where $O_{2, k}$ is the output of layer $2, w_{k}$ is the firing strength of each if-then rule. So each node in this layer is labelled " $\Pi$ " in Fig.4.

Layer 3: The third layer is to generate the normalized data by Eq. (7),

$$
O_{3, k}=\bar{w}_{k}=\frac{w_{k}}{\sum_{k=1}^{2} w_{k}}
$$

where $O_{3, k}$ is the output of layer $3, \bar{w}_{k}$ is the normalised firing strengths. So each node in this layer is labelled "N" in Fig.4.

Layer 4: The fourth layer is the consequence of if-then rules, which is expressed by Eq. (8)

$$
O_{4, k}=\bar{w}_{k}\left(p_{k} x^{\prime}+q_{k} y^{\prime}+r_{k}\right)(k=1,2)
$$

where $O_{4, k}$ is the output of layer $4, p_{k}, q_{k}$, and $r_{k}$ are consequence parameters that can be determined by least square method.

Layer 5: the fifth layer is the summation of the results collected from layer 4 (Sridevi and Nirmala, 2016), which is expressed by Eq. (9),

$$
O_{5}=\sum_{k=1}^{2} \bar{w}_{k}\left(p_{k} x^{\prime}+q_{k} y^{\prime}+r_{k}\right)
$$


where $O_{5}$ is the output of layer 5. During the ANFIS process, $80 \%$ of the total sample are viewed as a training set; the rest samples are treated as a testing set to check whether the ANFIS output is accurate and general enough.

\section{Case study}

In this section, the methodology mentioned above will be utilised for maintenance work in a power supply system of Beihai LNG terminal in Southern China. This power supply system is the key factor to guarantee the whole terminal especially the transfer arms running normally. During the lifetime of this power supply system, maintenance work is necessary to ensure the safety. The maintenance work is mainly a human factor related activity, so fuzzy CREAM could be applied to calculate the HEP data under real condition. The previous study shows the required HEP should be set at 0.002 (Zhang and Tan, 2016). In this paper, the research focuses on building a decision data pool through fuzzy CREAM, and constructing a general ranking system for decision-making to evaluate the safety promotion plan.

\subsection{Finding the HEP under real condition}

As inputs to the fuzzy CREAM process, four experienced experts are chosen to mark for each CPC. The evaluating questionnaire for CPC marking is shown in Appendix A, and the full mark is 100 . Therefore, for the CPC1 "the adequacy of organization", the four marks given by the four experts are $(85,70,80,85)$. Similarly, the rest CPCs' marks are displayed in Table 3.

Table 3. The marks of 9 CPCs.

\begin{tabular}{ccccc}
\hline CPC & Expert 1 & Expert 2 & Expert 3 & Expert 4 \\
\hline Adequacy of organization & 85 & 70 & 80 & 85 \\
Working condition & 65 & 70 & 55 & 70 \\
Adequacy of MMI and operational support & 80 & 75 & 80 & 80 \\
Availability of procedures/plans & 65 & 70 & 40 & 70 \\
Number of simultaneous goals & 65 & 60 & 50 & 60 \\
Available time & 65 & 50 & 65 & 65 \\
Time of day & 65 & 55 & 70 & 70 \\
Adequacy of training and experience & 65 & 60 & 70 & 70 \\
Crew collaboration quality & 80 & 80 & 85 & 80 \\
\hline
\end{tabular}

Then the fuzzy membership function is adopted to determine the linguistic variables in a numerical form. In such method, the linguistic variables can be explained by fuzzy sets and corresponding membership degrees. For example, those fuzzy sets used to explain CPC1 "Adequacy of organization" are Deficient $[a, b, c, d]=[0,0,10,40]$ Inefficient $[a, b, c, d]=[10,40,40,60]$, Efficient $[a, b, c, d]=[40$, $60,70,80]$, and Very-efficient $[a, b, c, d]=[70,80,100,100]$, where $[a, b, c, d]$ contains the four parameters for the describing the trapezoid membership function in Eq. (3). Likewise, all linguistic variables can be described, and Fig. 5 shows the results. 

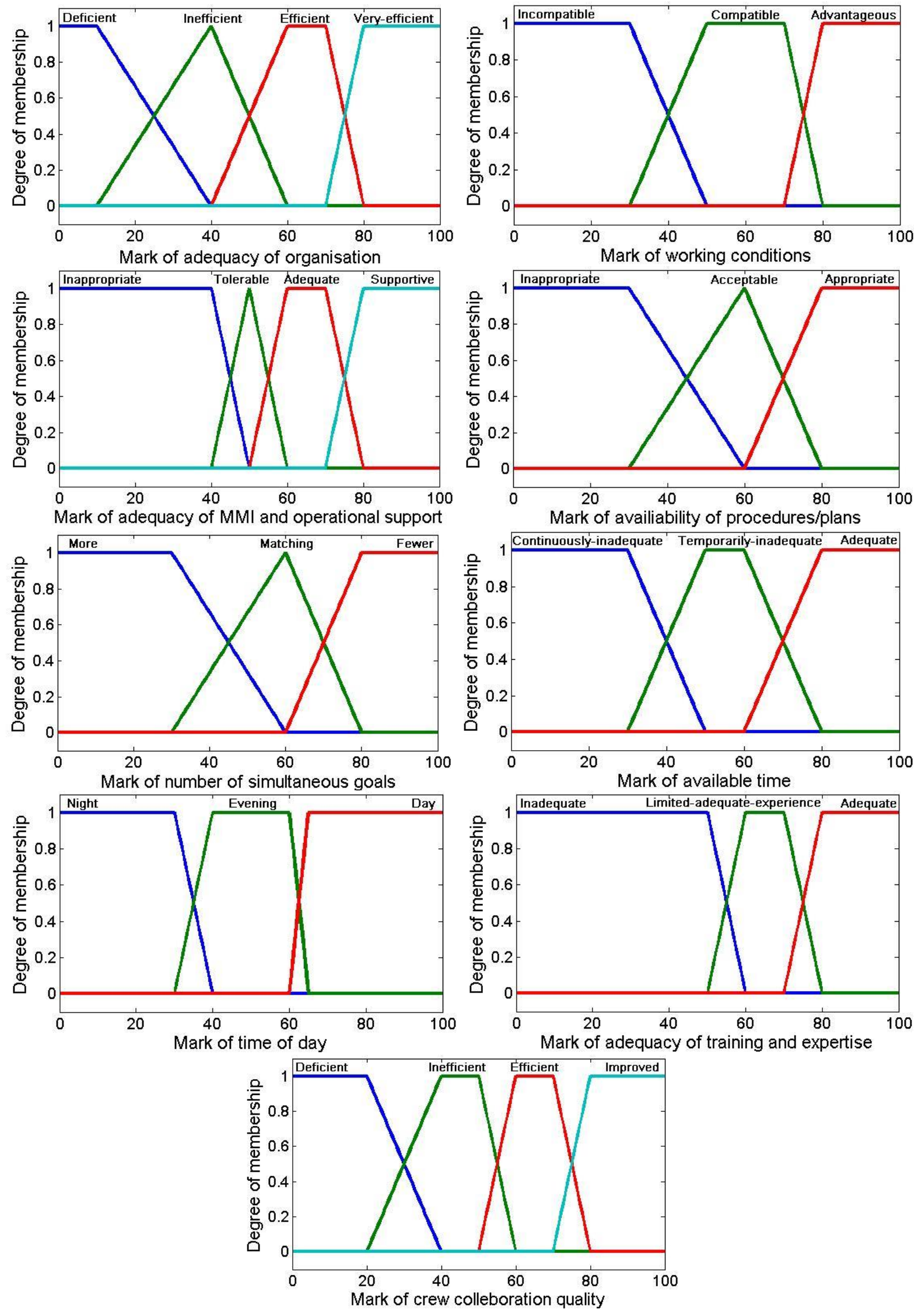

Fig.5.Membership curves for nine CPCs. 
As shown in Table 2, there are HEP intervals for each COCOM, then the fuzzy membership functions are implemented on it as well, and the logarithm is applied on each HEP interval to distinguish them clearly. As a result, Fig.6 displays the fuzzy membership curves.

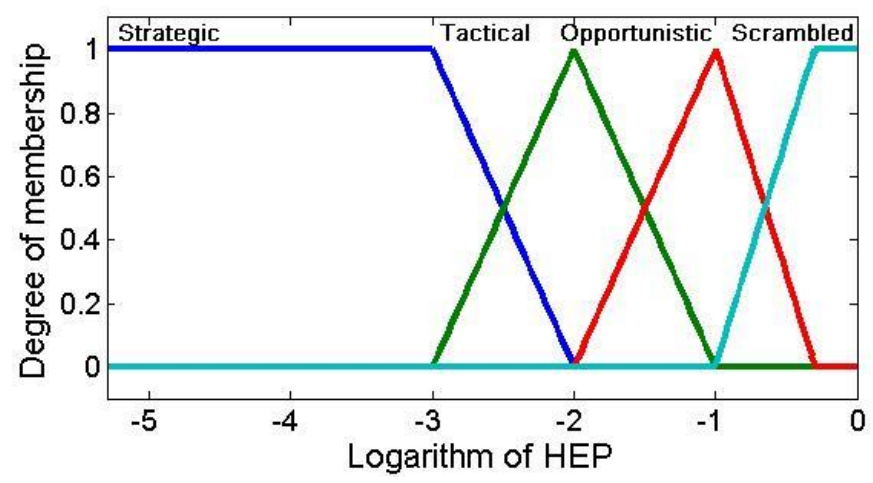

Fig.6. Membership curves of each COCOM.

As the four experts have differences, the weights of each expert in marking each CPC should also be determined. Fuzzy Analytical Hierarchy Process (FAHP) method is suitable to find each weight (Akkaya et al., 2015). As a result, the weights of each expert are identified by FAHP, which is shown in Table 4.

Table 4. The weight of each expert.

\begin{tabular}{lllll}
\hline & Expert 1 & Expert 2 & Expert 3 & Expert 4 \\
\hline Weight & 0.27 & 0.21 & 0.24 & 0.28 \\
\hline
\end{tabular}

After that, the final marks of each CPC can be deduced through Eq. (10).

$$
F_{i}=\sum_{j=1}^{N} \omega_{j} * a_{i j}(i=1,2 \cdots, 9)
$$

where $F_{i}$ is the final mark of $i$ th CPC, $N$ is the total number of experts, here $N$ equals $4, \omega_{j}$ is the weight of $j$ th expert in CPC marking, $a_{i j}$ is the mark given by $j$ th expert for $i$ th CPC, which is defined in Table 3. As a result, the final marks of each CPC are displayed below.

Table 5. Final marks of each CPC.

\begin{tabular}{llllllllll}
\hline & CPC1 & CPC2 & CPC3 & CPC4 & CPC5 & CPC6 & CPC7 & CPC8 & CPC9 \\
\hline Marks & 80.65 & 65.05 & 78.95 & 61.45 & 58.95 & 61.85 & 65.5 & 66.55 & 81.2 \\
\hline
\end{tabular}

Based on fuzzy membership function in Fig. 5 and fuzzy logic, the final membership level of each CPC can be determined as shown in Table 6 .

Table 6. Membership level of each CPC.

\begin{tabular}{|c|c|c|}
\hline No. & $\mathrm{CPC}$ & Fuzzy data \\
\hline 1 & Adequacy of organization & Very efficient (1.0) \\
\hline 2 & Working condition & Compatible (1.0) \\
\hline 3 & Adequacy of MMI and operational support & Supportive $(0.895)$, Adequate $(0.105)$ \\
\hline 4 & Availability of procedures/plans & Acceptable $(0.9275)$, Appropriate $(0.0725)$ \\
\hline 5 & Number of simultaneous goals & $\begin{array}{l}\text { Matching current capacity }(0.965) \text {, } \\
\text { Continuous inadequate }(0.035)\end{array}$ \\
\hline 6 & Available time & $\begin{array}{c}\text { Temporarily inadequate }(0.9075), \\
\text { Adequate }(0.0925)\end{array}$ \\
\hline 7 & Time of day & Day (1.0) \\
\hline 8 & Adequacy of training and experience & Adequate with limited experience (1.0) \\
\hline 9 & Crew collaboration quality & Very efficient (1.0) \\
\hline
\end{tabular}

The final fuzzy membership degree of COCOM is 0.895 (tactical) and 0.0925 (strategic), and according to the COA defuzzification method shown in Eq. (4), the calculated HEP equals 0.0044 
which fails to achieve the HEP requirement (0.002). Therefore, under this situation, the required HEP 0.002 can be set as the target value which should be ensured in optimization, and the COA equation shown in Eq. (4) can be viewed as an objective function which should be optimized. Then, based on the flow chart of methodology shown in Fig.1, GA will be implemented on the defuzzification equation to identify the best parameters and meanwhile to ensure the calculated HEP is less than 0.002 .

\subsection{GA in defuzzification process}

In the project, the membership degrees of COCOM only cover "strategic" and "tactical"; so based on the fuzzy membership curve in Fig.6, and the trapezoid membership function defined as Eq. (3), their fuzzy membership functions are simplified as below:

$$
\begin{aligned}
& \mu_{s}(x)=\left\{\begin{array}{lr}
s & \left(-5.3<x<x_{1}\right) \\
-x-2 & \left(x_{1}<x<-2\right)
\end{array}\right. \\
& \mu_{t}(x)=\left\{\begin{array}{lr}
x+3 & \left(-3<x<x_{2}\right) \\
t & \left(x_{2}<x<x_{3}\right) \\
-x-1 & \left(x_{3}<x<-1\right)
\end{array}\right.
\end{aligned}
$$

where $\mu_{s}(x)$ is the membership function which covers "strategic" control mode, $x$ is the logarithm of corresponding HEP, $s$ is the membership degree of strategic control mode which is a constant with value range from 0 to $1, \mu_{t}(x)$ is the membership function which covers tactical control mode, $t$ is the membership data of tactical control mode which is also a constant ranging from 0 to 1 . Then, by applying COA method on Eq. (11) and (12) together, the objective function can be expanded as Eq. (13).

$$
\begin{aligned}
& \int_{-5.3}^{x_{1}} s x d x+\int_{x_{1}}^{-2}(-x-2) x d x+\int_{-3}^{x_{2}}(x+3) x d x \\
& \mathrm{y}=\frac{+\int_{x_{2}}^{x_{3}} t x d x+\int_{x_{3}}^{-1}(-x-1) x d x}{\int_{-5.3}^{x_{1}} s d x+\int_{x_{1}}^{-2}(-x-2) d x+\int_{-3}^{x_{2}}(x+3) d x} \\
& +\int_{x_{2}}^{x_{3}} t d x+\int_{x_{3}}^{-1}(-x-1) d x
\end{aligned}
$$

Based on Fig.6, Eq. (11), and Eq. (12), the constraints of $x_{1}, x_{2}$, and $x_{3}$ are $x_{1} \in(-3,-2), x_{2} \in$ $(-3,-2), x_{3} \in(-2,-1)$, and $x_{2}+x_{3}=-4$; besides, the constraint of " $s$ " (membership degree of strategic control mode) is $s=-x_{1}-2$, and constraint of " $t$ " (membership degree of tactical control mode) is $t=x_{2}+3$. As the requirement of HEP is less than 0.002, the objective of Eq. (13) is less than -2.699 $\left(\log _{10} 0.002\right)$. After that, giving GA optimization on Eq. (13) within the objective and constraints, then the results are: $x_{1}=-2.206, x_{2}=-2.229, x_{3}=-1.771$ which are presented in Fig.7. Consequently, the target membership degree of strategic control mode " $s$ " equals 0.206 and tactical control mode " $t$ " equals 0.771 .

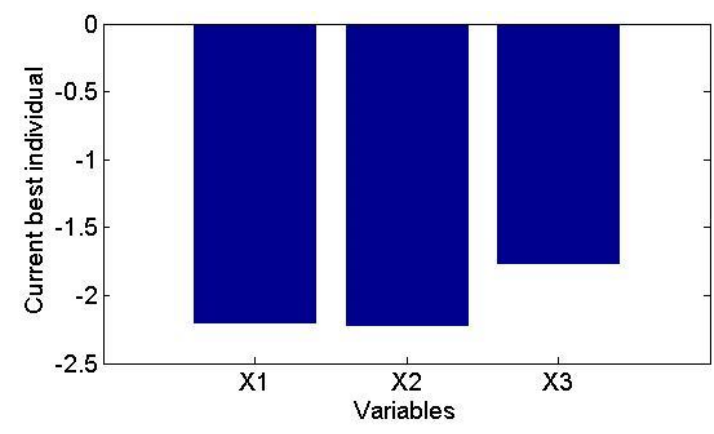


Fig.7. The result of GA optimization for HRA.

\subsection{Identify potential promotion plans}

The initial membership degrees ( 0.895 for tactical control mode, 0.0925 for strategic control model) are different with the target membership degrees $(0.771$ for tactical control mode, and 0.206 for strategic control mode), which means the original calculated HEP fails to meet the required HEP. Therefore, some specific plans should be worked out. According to the information from Fig.5, Table 1 and Table 6, it can be seen that there is some room to improve the performance of some CPCs (CPC2, CPC3, CPC4, CPC6, CPC8) from "not significant to reliability" to "improved to reliability". Therefore, by improving the performance marks of some CPCs, and based on the fuzzy membership function curves of each CPC in Fig.5, the fuzzy membership degrees of some CPCs will be changed. Then based on the "fuzzy logic operation rules" in Eq. (2), the fuzzy membership function curves of each COCOM in Fig.6, and defuzzification method in Eq. (4), the revised HEP can be calculated, which may be different from the original. Besides, as described in Table 1, the CREAM evaluation form contains nine CPCs, and each of them involves some sub-influencing factors which are shown in Appendix A, it is possible that through changing the performance data of some CPCs to reach the requirement. For instance, according to Appendix A, if improving the safety bonus, then performance mark of CPC2 (working condition) will be increased, and the membership degree of each COCOM will be changed as well as the corresponding calculated HEP. Thus, through similar way to improve the performance of some CPCs, a plenty of plans can be provided. For this project, 54 potential plans are selected, and three of them are listed below as examples.

1) Through improving the safety awards, providing more personal protective equipment, and replacing the old facility to high reliability equipment to ensure the human reliability can be maintained at the acceptable level.

2) Through recruiting higher qualified employee, giving enough expertise training on power supply systems, and periodically reviewing the employee's working performance to avoid the human errors.

3) Through improving the automatic level of operating process, and increasing the inherent safety level of equipment in power supply system; besides, increasing the number of operators in maintenance work to enhance current working capacity so that the operator can finish the job goals on time.

Having a plenty of plans available, it is necessary to evaluate all the available plans and then to build a standard model for current and future decision making in this system.

\subsection{Constructing a standard multi-criteria decision making model}

Selecting the most suitable plan is a typical MCDM problem. As many decisions are motivated by economy (Borysiewicz et al., 2015), this study considers the economy performance in MCDM process. Besides, reasonable time duration is helpful to take a plan into practice friendly, so it is a considerable factor for plan evaluation. In addition, since the objective is to improve the human reliability, the reliability performance of each plan should be evaluated. Therefore, three attribute ratios have been used to evaluate each plan, they are, "Economy ratio", "Practicability ratio", and "Reliability ratio". The "Economy ratio" and "Practicability ratio" are to display the performance of a plan on money investment and the performance of estimated time duration for a chosen plan. In addition, this study deems system reliability is the combination of human reliability and facility reliability together. Namely, operators and facilities are both ensuring the system normal running 
(Zhang and Tan, 2016), and some potential plans can improve the facility reliability as well, so in this study, the "Reliability ratio" represents the integrated performance on human reliability and facility reliability together. Then the value of each attribute ratio is collected from Eq. (14)

$$
A_{r}=\frac{v^{c}-v^{f}}{v^{c}-v^{i}}
$$

where $A_{r}$ is the ratio for the attribute, $v^{c}$ is the critical value that cannot be exceeded, $v^{f}$ is the final value after implementing the plan, and $v^{i}$ is the initial value before taking the decision. With the attribute ratios of each plan, the experts can give evaluated mark on each plan based on their experience and knowledge. The attribute ratios and the corresponding evaluated marks are shown in Appendix B, and plan 5 "to increase the available time during the maintenance work" is best one.

Thereafter, ANFIS is introduced to build a decision making system to simulate the experts' evaluation so that the future update decision making results can be collected without experts' judgement. In this study, $80 \%$ of the samples in Appendix B are viewed as the training set to construct an ANFIS model to simulate the experts' evaluation for supporting the MCDM process. The attribute ratios are used as inputs for ANFIS, the evaluated marks of each plan are viewed as expected results for ANFIS output, and the error tolerance of training process is set at 0 . Besides, Gaussian membership function, which is determined by Eq. (15), is adopted to express each attribute (inputs).

$$
\operatorname{Gaussian}\left(x_{i n}, \bar{x}, \sigma\right)=e^{-\frac{1}{2}\left(\frac{x_{i n}-\bar{x}}{\sigma}\right)^{2}}
$$

where $x_{i n}$ is the input data of this ANFIS, $\bar{x}$ is the centre of Gaussian the membership function curve centre, and $\sigma$ is the width of the Gaussian membership curve.. In each input ("Practicability ratio", "Economy ratio", and "Reliability ratio"), three membership degrees are involved; the structure of ANFIS model is presented in Fig.8.

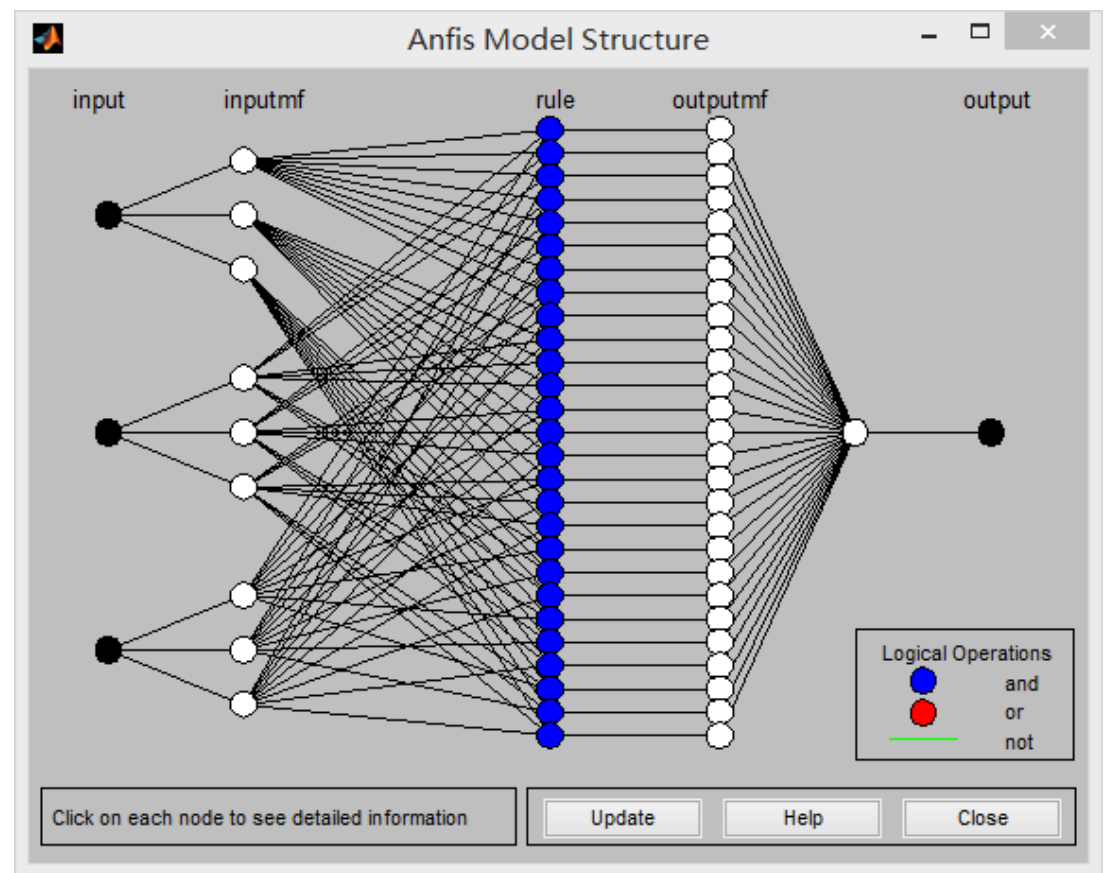

Fig.8. The structure of ANFIS model 
After 1000 iterations, their fuzzy membership functions of each attribute ratio are automatically adjusted by the gradient decent method. Fig.9 gives the final fuzzy membership function curves of each attribute ratio. Besides, according to input data and ANFIS output results after 1000 iterations, the relationships between each two of three attribute ratios and the ANFIS outputs in training process are explained by Fig.10. Fig.10(a) displays the relationship among the "Practicability ratio", "Economy ratio", and ANFIS output under the situation that "Reliability ratio" equals to 2.384. Fig. 10(b) shows how "Practicability ratio" and "Reliability ratio" work together to change the ANFIS output, when "Economy ratio" is 1.375 . Fig.10(c) illustrates the contribution of "Reliability ratio" and "Economy ratio" to ANFIS output, when the "Practicability ratio" is -0.5 .

Meanwhile, based on three inputs and ANFIS output, Fig.11 uses a 4D diagram to illustrate the relationship among "Practicability ratio", "Economy ratio", "Reliability ratio" and ANFIS output, and a colour bar is displayed in Fig.11 to illustrate the change of ANFIS output value by changing colour from blue to red. Moreover, the comparison between ANFIS outputs of the training set and their real evaluating output scores are shown in Fig.12, and the rest 20\% samples (testing set) are compared with the ANFIS results as well, which is shown in Fig.13. Then, the Mean Square Error (MSE) and Rvalue of testing set can be calculated by Eq. (16) and Eq. (17).

$$
\begin{gathered}
M S E=\frac{1}{\varphi} \sum_{i=1}^{\varphi}\left(\Omega_{\text {ANFIS }}-\Omega_{\text {real }}\right)^{2} \\
R^{2}=1-\frac{\sum_{i=1}^{\varphi}\left(\Omega_{\text {ANFIS }}-\Omega_{\text {real }}\right)^{2}}{\sum_{i=1}^{\varphi}\left(\Omega_{\text {ANFIS }}-\Omega_{\text {aver }}\right)^{2}}
\end{gathered}
$$

Where, $\varphi$ is the number of testing sample (in this case $\varphi=12$ ), $\Omega_{\text {ANFIS }}$ represents the ANFIS output, $\Omega_{\text {real }}$ is the real evaluating output, and $\Omega_{\text {aver }}$ is the average value of real evaluating output, then the MSE of testing set is $2.21 \times 10^{-3}$, and the R-value of the testing set is $9.85 \times 10^{-1}$. It can be concluded that the error of both training set and testing set is small, so the ANFIS model is reliable.
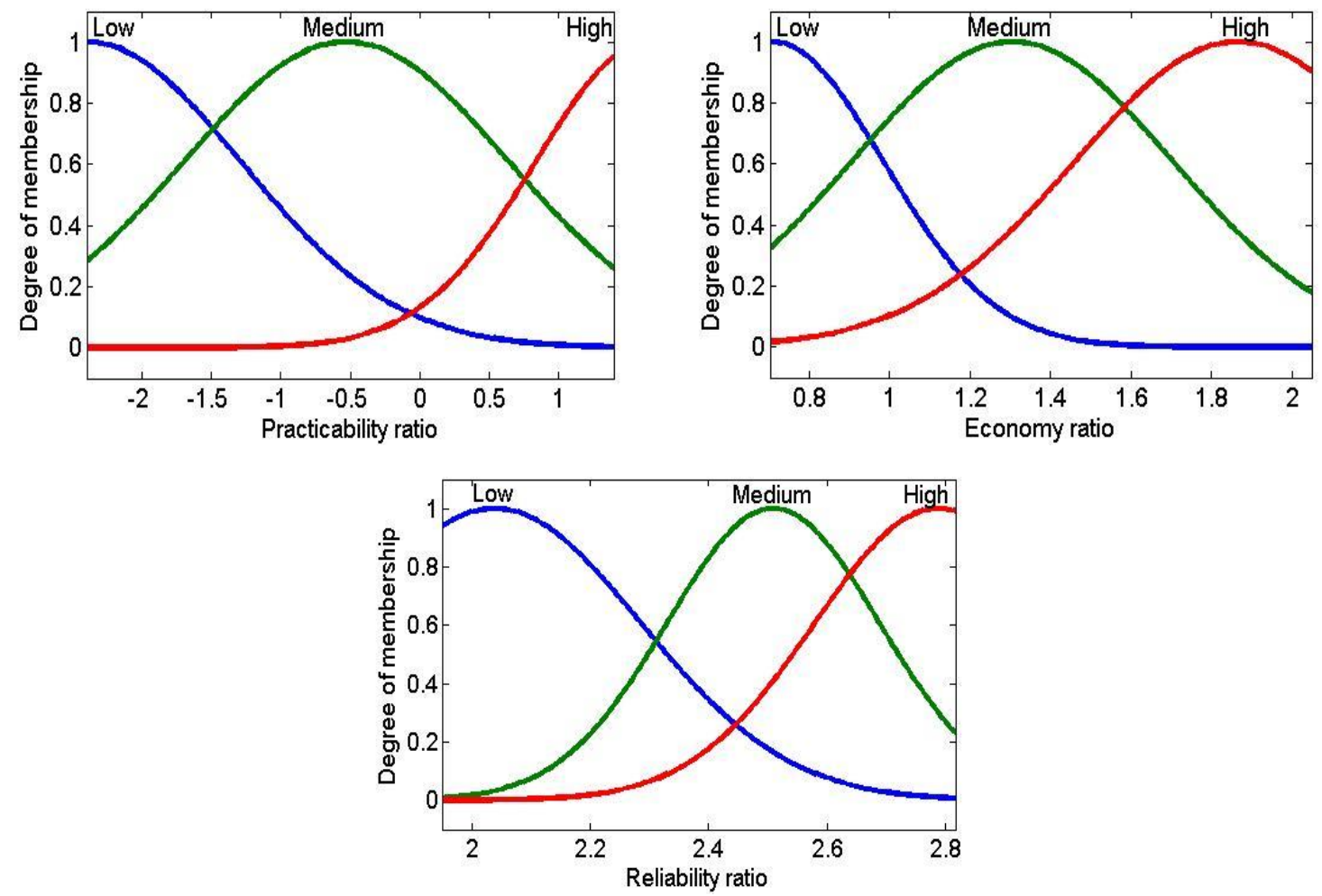
Fig.9. The membership levels of three inputs.

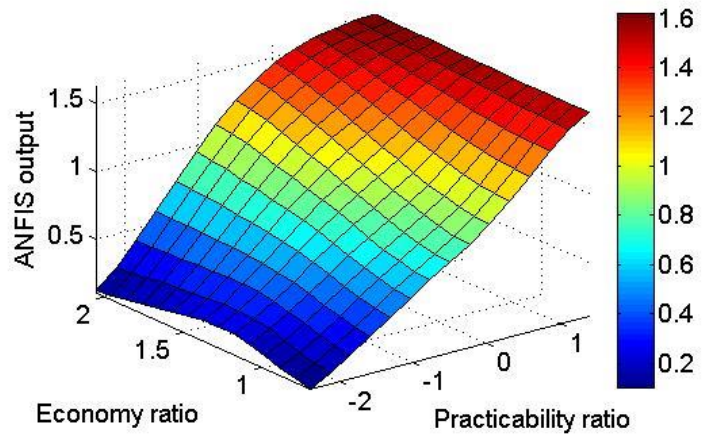

(a)

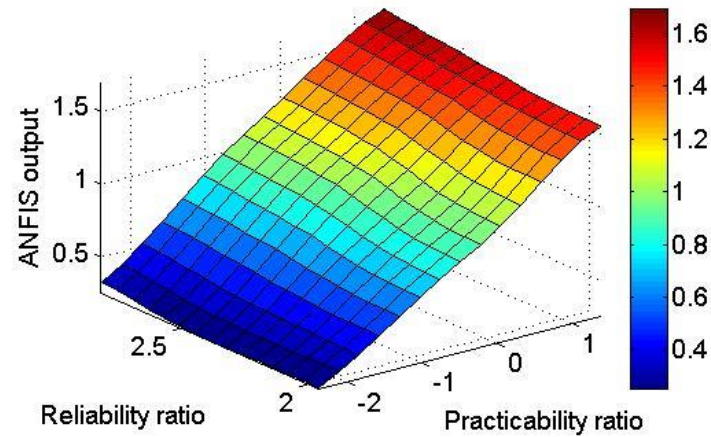

(b)

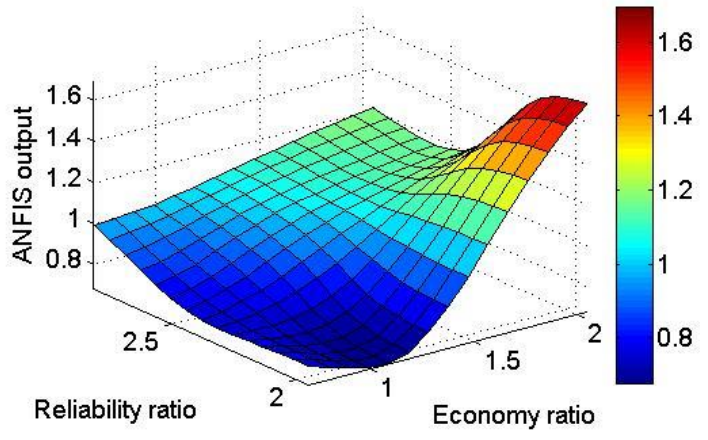

(c)

Fig.10. The relationship between each two of three attributes and ANFIS outputs.

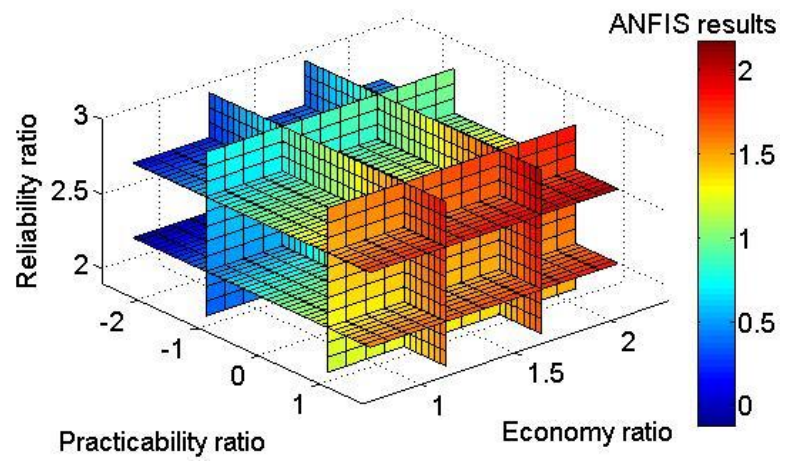

Fig.11. The relationship between each attribute and output value

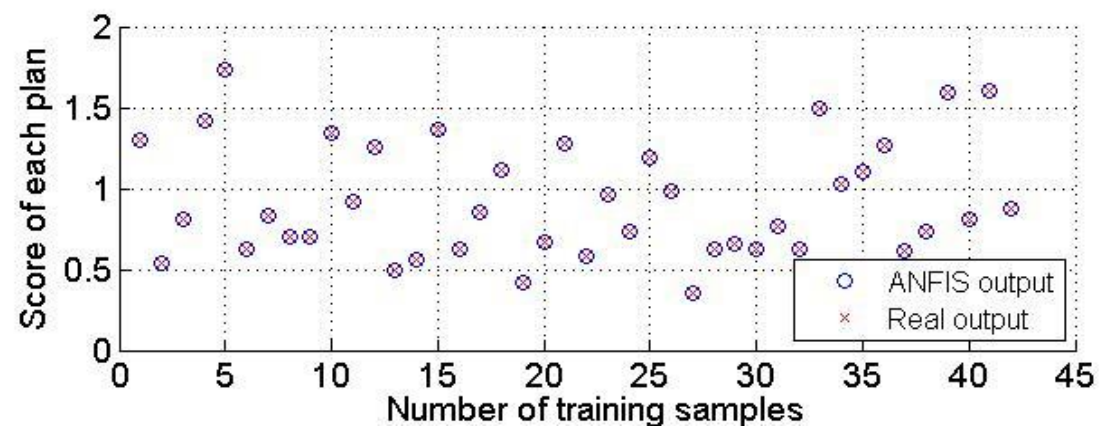


Fig.12. The results of ANFIS training outputs and real outputs of training set

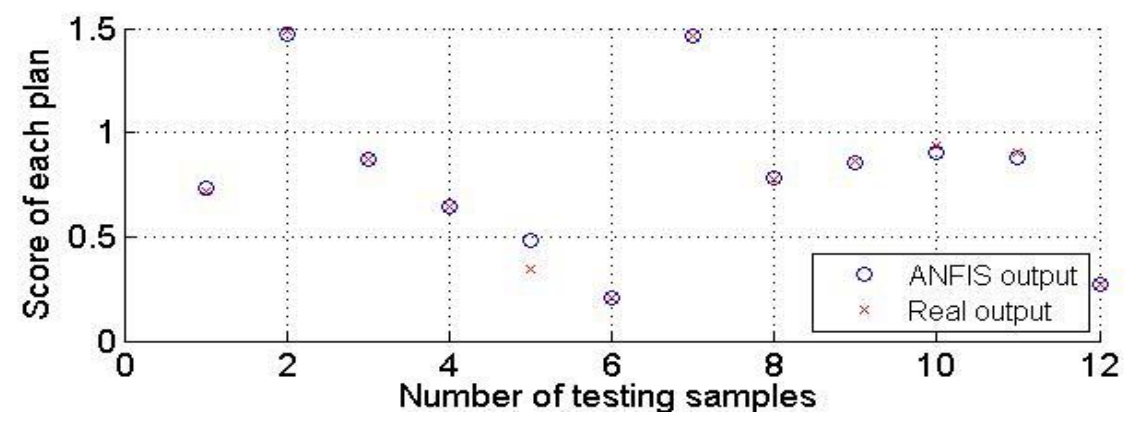

Fig.13. The results of ANFIS training outputs and real outputs of testing set.

\section{Conclusion and future work}

In this study, fuzzy CREAM is adopted to identify the membership degrees of each COCOM and to calculate HEP data. Then, the GA optimization can be applied to the defuzzification equation with the required HEP and constraints to find the target membership degree of each COCOM, when the original calculated HEP fails to meet the requirement. After that, facing the target membership degree of each COCOM, many solutions will be worked out based on fuzzy CREAM evaluation form and fuzzy logic rules. Finally, an experts' evaluation results based ANFIS decision supporting model is constructed. In summary, the proposed method conducts an integrating model for human reliability promotion plan finding and evaluating based on a power supply system of Beihai LNG terminal, and it extends the applicability of fuzzy CREAM from HRA method to a medium that can identify the best way to achieve the reliability objective. The following highlights are made with respect to this research:

1) Extending the original CREAM from a simply HRA method to a method which can generate a pool of plans for safety promotion.

2) The target fuzzy membership degrees of human control modes are identified by GA optimization.

3) Providing a mathematical and logical way to construct a standard and robust model for decision making to improve the safety.

The paper contributes to on-going efforts towards the improvement of safety for power supply system in LNG terminal, since power supply system is the crucial factor to ensure LNG transfer arm normal running during LNG loading/unloading process, and the accidents' frequency during loading/unloading process is high. According to the chosen example and the final results, the best plan is to increase the available time during the maintenance work. Furthermore, the proposed method can be used by senior safety engineers, or third party safety assessment companies to calculate the HEP and to reasonably identify and evaluate all potential safety promotion plans. In addition, this method can be applied for other human related cases and more involved in QRA process for other industry as well.

CREAM has some drawbacks; for instance, it focuses on how action fails, it only focuses on human being, and it lends support to the concept of "error" (Zhou et al., 2017). However, compared with other HRA methods, CREAM considers more factors which can affect human operations, so it is more suitable to be transferred to a medium for plan producing. Besides, by introducing fuzzy logic into CREAM, the unclear boundaries of each COCOM and each level in CPC can be tackled, and 
original CREAM can be quantified. However, as lack of data and standards, this study involves some experts' evaluation, which limits this study, so when applying this method, the high experienced staffs are necessary. In addition, this study still requires some improvements: the CPCs and their corresponding sub-influence factors should be specially designed for LNG terminal, and the relationship, interaction and weight among each revised CPC should be reconsidered and calculated as well. Therefore, in next research, those improvements will be engaged.

\section{Acknowledgement}

We would like to give sincerely thank to Zhonghe Zhang, the principle expert in Sinopec and other relevant staff in Beihai LNG terminal for their valuable and constructive support during the development of this work. We would also like to express our very great appreciation to the respected reviewers. Their valuable suggestions and comments have enhanced the strength of this paper.

\section{Appendix A. Questionnaire for CREAM evaluation}

\begin{tabular}{ll}
\hline CPC & Questions \\
\hline CPC1 Adequacy of organization & 1.1 Do they have enough departments to cover each activity for \\
& maintenance and other related work? \\
& 1.2 Does each department understand their responsibility? \\
& 1.3 Do they have periodically departmental check to ensure \\
& their performance? \\
& 2.1 Do they provide enough personal protective equipment? \\
CPC2 Working condition & are easy to operate? \\
& 2.3 Are the salary and bonus sufficient to encourage staff to \\
& follow the safety rule?
\end{tabular}

CPC3 Adequacy of Man Machine Interface (MMI) and operational support

CPC4 Availability of procedures/plans

CPC5 Number of simultaneous goals

CPC6 Available time

CPC7 Time of day

CPC8 Adequacy of training and experience

CPC9 Crew collaboration quality
3.1 Can the alarm and emergency shutdown system prevent the consequences of failure?

3.2 Does the distance automatic control provide enough operational support?

4.1 Do they have sufficient maintenance and emergency plans?

4.2 Do they have enough supporting equipment and component for the maintenance work?

5.1 Do they have enough operators to finish the maintenance work on time?

5.2 Can operators all receive periodically expertise training to update their skills for the maintenance work?

6.1 Do they have enough time to finish all the maintenance work?

7.1 Do they usually work in the daytime?

7.2 Do they usually work in the evening?

7.3 Do they usually work at night?

8.1 Do they recruit experienced staff?

8.2 Do they provide enough expertise training before work?

8.3 Are there any periodically check to evaluate the performance of each operator?

9.1 How is the safety culture in this LNG terminal?

9.2 Do all operators understand their responsibility?

9.3 Are all operators suitable for their maintenance work?

Appendix B. Raw data for ANFIS

\begin{tabular}{lll}
\hline Sample & Input & Output \\
\hline
\end{tabular}




\begin{tabular}{|c|c|c|c|c|}
\hline number & $\begin{array}{c}\text { Practicability } \\
\text { ratio }\end{array}$ & $\begin{array}{c}\text { Economy } \\
\text { ratio }\end{array}$ & $\begin{array}{c}\text { Reliability } \\
\text { ratio }\end{array}$ & $\begin{array}{l}\text { Final } \\
\text { score }\end{array}$ \\
\hline 1 & 0.3448 & 0.8778 & 2.7003 & 1.2970 \\
\hline 2 & -1.4348 & 1.6980 & 2.0615 & 0.5410 \\
\hline 3 & -1.3961 & 1.6714 & 2.8103 & 0.8120 \\
\hline 4 & 1.0000 & 1.3500 & 1.9515 & 1.4170 \\
\hline 5 & 1.3950 & 0.9475 & 2.6673 & 1.7330 \\
\hline 6 & -0.7528 & 1.0650 & 1.9515 & 0.6300 \\
\hline 7 & -0.7100 & 1.0000 & 2.5339 & 0.8360 \\
\hline 8 & -1.1850 & 1.0195 & 2.7003 & 0.7040 \\
\hline 9 & -1.8298 & 2.0480 & 2.7432 & 0.7010 \\
\hline 10 & 0.3448 & 1.0528 & 2.7000 & 1.3390 \\
\hline 11 & -1.2442 & 2.0214 & 2.6905 & 0.9170 \\
\hline 12 & 0.3448 & 0.7028 & 2.6868 & 1.2500 \\
\hline 13 & -1.4348 & 0.8966 & 2.4668 & 0.4900 \\
\hline 14 & -1.4348 & 0.8699 & 2.6958 & 0.5640 \\
\hline 15 & 0.5411 & 0.9399 & 2.6203 & 1.3650 \\
\hline 16 & -1.4511 & 1.6980 & 2.3276 & 0.6270 \\
\hline 17 & -1.2472 & 1.6675 & 2.7693 & 0.8580 \\
\hline 18 & 0.3436 & 0.7971 & 2.2306 & 1.1130 \\
\hline 19 & -1.8461 & 1.5056 & 2.3355 & 0.4220 \\
\hline 20 & -1.6398 & 1.4789 & 2.8103 & 0.6660 \\
\hline 21 & 0.3448 & 0.8253 & 2.6753 & 1.2760 \\
\hline 22 & -1.4348 & 1.6456 & 2.2129 & 0.5810 \\
\hline 23 & -1.0011 & 1.6189 & 2.8167 & 0.9640 \\
\hline 24 & -0.4270 & 0.8934 & 1.9724 & 0.7300 \\
\hline 25 & 0.5424 & 0.8778 & 2.1742 & 1.1940 \\
\hline 26 & -0.4421 & 0.8934 & 2.7096 & 0.9820 \\
\hline 27 & -1.8358 & 1.7790 & 2.3005 & 0.4790 \\
\hline 28 & -1.4348 & 1.6980 & 2.3040 & 0.6260 \\
\hline 29 & -1.8358 & 1.7790 & 2.8066 & 0.6570 \\
\hline 30 & -1.8020 & 1.6815 & 2.7531 & 0.6280 \\
\hline 31 & -1.3961 & 1.5839 & 2.7531 & 0.7710 \\
\hline 32 & -1.7911 & 1.6284 & 2.7531 & 0.6200 \\
\hline 33 & 1.0000 & 0.9685 & 2.4464 & 1.4990 \\
\hline 34 & -0.2705 & 1.1750 & 2.4464 & 1.0270 \\
\hline 35 & -0.2705 & 1.1330 & 2.6928 & 1.1040 \\
\hline 36 & 0.6445 & 0.8600 & 2.2873 & 1.2710 \\
\hline 37 & -1.0125 & 0.9475 & 2.2873 & 0.6130 \\
\hline 38 & -1.0125 & 0.8600 & 2.6928 & 0.7340 \\
\hline 39 & 0.9012 & 1.2170 & 2.6619 & 1.5930 \\
\hline 40 & -0.7528 & 1.0125 & 2.5120 & 0.8140 \\
\hline 41 & 1.1975 & 0.9370 & 2.5385 & 1.6040 \\
\hline 42 & -0.7528 & 1.0020 & 2.6928 & 0.8740 \\
\hline $43^{\mathrm{st}}$ & -0.7528 & 0.9635 & 2.3251 & 0.7360 \\
\hline $44^{\mathrm{st}}$ & 1.0790 & 0.8950 & 2.3251 & 1.4710 \\
\hline $45^{\mathrm{st}}$ & -0.7528 & 0.9600 & 2.7078 & 0.8700 \\
\hline $46^{\mathrm{st}}$ & -1.2100 & 1.0000 & 2.5697 & 0.6430 \\
\hline $47^{\mathrm{st}}$ & -1.9594 & 1.0650 & 2.5635 & 0.3500 \\
\hline $48^{\mathrm{st}}$ & -2.3950 & 1.0000 & 2.7025 & 0.2040 \\
\hline $49^{\text {st }}$ & 0.9210 & 0.8950 & 2.4835 & 1.4620 \\
\hline $50^{\mathrm{st}}$ & -0.7528 & 0.9775 & 2.4454 & 0.7820 \\
\hline $51^{\mathrm{st}}$ & -0.7528 & 0.8950 & 2.7189 & 0.8580 \\
\hline $52^{\mathrm{st}}$ & -0.7528 & 1.2400 & 2.6258 & 0.9080 \\
\hline
\end{tabular}




\begin{tabular}{ccccc}
$53^{\text {st }}$ & -0.8150 & 1.2275 & 2.6258 & 0.8800 \\
$54^{\text {st }}$ & -2.3950 & 1.2275 & 2.7361 & 0.2700 \\
\hline "st" represents the sample for testing
\end{tabular}

\section{References}

Abbasi, B., Mahlooji, H., 2012. Improving response surface methodology by using artificial neural network and simulated annealing. Exp. Syst. Appl. 39, 3461-3468.

Akkaya, G., Turanoglu, B., Oztas, S., 2015. An integrated fuzzy AHP and fuzzy MOORA approach to the problem of industrial engineering sector choosing. Exp. Syst. Appl. 42, 9565-9573.

Akyuz, E., 2015. Quantification of human error probability towards the gas inerting process on-board crude oil tankers. Saf. Sci. 80, 77-86.

Akyuz, E., Celik, M., 2015. A methodological extension to human reliability analysis for cargo tank cleaning operation on board chemical tanker ships. Saf. Sci. 75, 146-155.

Azadeh, A., Gaeini, Z., Motevali, S., Nasirian, B., 2016. A unique adaptive neuro fuzzy inference system for optimum decision making process in a natural gas transmission unit. Journal of Natural Gas Science and Engineering. 34, 472-485.

Bedford, T., Bayley, C., Revie, M., 2013. Screening, sensitivity, and uncertainty for the CREAM method of human reliability analysis. Reliabil. Eng. Syst. Saf. 115, 100-110.

Borysiewicz, M., Kowal , K., Potempski, S., 2015. An application of the value tree analysis methodology within the integrated risk informed decision making for the nuclear facilities. Reliabil. Eng. Syst. Saf. 139, 113-119.

Casal, A., Olsen, H., 2016. Operational risks in QRAs. Chem. Eng. Trans. 48, 589-594.

Dhillon, B.S., 2007. Human Reliability and Error in Transportation Systems. Springer Science \& Business Media, London.

Golmohammadi, D., 2011. Neural network application for fuzzy multi-criteria decision making. Int. J. Prod. Econ. 131, 490-504.

He, X., Wang, Y., Shen, Z., Huang, X., 2008. A simplified CREAM prospective quantification process and its application. Reliabil. Eng. Syst. Saf. 93, 298-306.

Hollnagel, E., 1998. Cognitive Reliability and Error Analysis Method (CREAM). Elsevier Science Ltd., Oxford, UK.

Innal, F., Dutuit, Y., Chebila, M., 2015. Safety and operational integrity evaluation and design optimization of safety instrumented systems. Reliabil. Eng. Syst. Saf. 134, 32-50.

Kim, B.J., Bishu, R.R., 2006. Uncertainty of human error and fuzzy approach to human reliability analysis. Int. J. Uncertain. Fuzz. 14(1), 111-129.

Konak, A., Coit, D.W., Smith, A.E., 2006. Multi objective optimization using genetic algorithms: a tutorial. Reliabil. Eng. Syst. Saf. 91(9), 992-1007.

Konstandinidou, M., Nivolianitou, Z., Kiranoudis, C., Markatos, N., 2006. A fuzzy modelling application of CREAM methodology for human reliability analysis. Reliabil. Eng. Syst. Saf. 91(6), 706-716.

Marseguerra, M., Zio, E., Martorell, S., 2006. Basics of genetic algorithms optimization: state-of-theart survey. Reliabil. Eng. Syst. Saf. 91(9), 977-991.

MATLAB, R2009bversion, 2009. TheMathWorks. [online] Available at: 〈www.mathworks.com>.

Özkan, G., İnal, M., 2014. Comparison of neural network application for fuzzy and ANFIS approaches for multi-criteria decision making problems. Appl. Soft Comput. 24, 232-238.

Ribeiro, A.C., Sousa, A.L., Duaete, J.P., Frutuoso e Melo, P.F., 2016. Human Reliability analysis of the Tokai-Mura accident through a THERP-CREAM and expert opinion auditing approach. Saf. Sci. 87, 269-279. 
Sarkheyli, A., Zain, A., Sharif, S., 2015. Robust optimization of ANFIS based on a new modified GA. Neurocomputing 166, 357-366.

Sridevi, S., Nirmala, S., 2016. ANFIS based decision support system for prenatal detection of Truncus Arteriosus congenital heart defect. Appl. Soft Comput. 46, 577-587.

Sun, Z., Li, Z., Gong, E., Xie, H., 2012. Estimating the human error probability using a modified CREAM. Reliabil. Eng. Syst. Saf. 100, 28-32.

Swain, A.D., 1990. Human reliability analysis: Need, status, trends and limitations. Reliabil. Eng. Syst. Saf. 29(3), 301-313.

Torres-Echeverria, A.C., Martorell, S., Thompson, H.A., 2009. Design optimization of a safetyinstrumented system baselld on RAMS+C addressing IEC61508 requirements and diverse redundancy. Reliabil. Eng. Syst. Saf. 94, 162-179.

Turan, O., El-laden, S.B., 2012. Human reliability analysis-Taxonomy and praxes of human entropy boundary conditions for marine and offshore applications. Reliabil. Eng. Syst. Saf. 98, 43-54.

Ung, S.T., 2015. A weighted CREAM model for maritime human reliability analysis. Saf. Sci. 72, 144-152.

Ung, S.T., Shen, W.M., 2011. A novel human error probability assessment using fuzzy modelling. Risk Anal. 31, 745-757.

Vanem, E., Antão, P., Østvik, I., Comas, F., 2008. Analysing the risk of LNG carrier operations, Reliabil. Eng. Syst. Saf. 93 (9), 1328-1344.

Wei, L.Y., 2016. A hybrid ANFIS model based on empirical mode decomposition for stock time series forecasting. Appl. Soft Comput. 42, 368-376.

Wiegmann, D.A., Shappell S.A., 2001. A Human Error Analysis of Commercial Aviation Accidents Using the Human Factors Analysis and Classification System (HFACS). Springfield, Virginia.

Yang, Z.L., Bonsall, S., Wall, A., Wang, J., Usman, M., 2013. A modified CREAM to human reliability quantification in marine engineering. Ocean Eng. 58, 293-303.

Zhang, R., Tan, H., 2016. Multi-objective Optimization of Power Supply System for Shipping LNG Off-loading Process Based on Switching Markov Chain and Genetic Algorithm. Chem. Eng. Trans. 48, 697-702.

Zhou, Q., Wong, Y.D., Xu, H., Thai, V.V., Loh, H.S., Yuen, K.F., 2017. An enhanced CREAM with stakeholder-graded protocols for tanker shipping safety application. Saf. Sci. 95, 140-147. 